\title{
Cupuassu (Theobroma grandiflorum) pulp, probiotic, and prebiotic: Influence on color, apparent viscosity, and texture of goat milk yogurts
}

\author{
Marion P. Costa, Beatriz S. Frasao, Adriana Cristina O. Silva, Mônica Q. Freitas, Robson M. Franco, \\ and Carlos A. Conte-Junior ${ }^{1}$ \\ Department of Food Technology, Fluminense Federal University, CEP 24230-340, Niterói, RJ, Brazil
}

\section{ABSTRACT}

Cupuassu is an acidic fruit that has a characteristic aroma, flavor, and texture; its fiber-rich pulp can provide a different consistency than other fruit pulps. Goat milk is an excellent source of amino acids, fatty acids, and minerals, and is widely used for processing fermented milks, such as yogurt. However, compared with cow milk yogurts, it is difficult to make goat milk yogurts with a good consistency. Therefore, it is necessary to use certain technological strategies. This study was carried out to investigate the possibility of adding cupuassu pulp, probiotic (Lactobacillus acidophilus LA5), and prebiotic (inulin) to improve the texture of goat milk yogurt. A total of 6 treatments were performed: natural (N), probiotic (Pro), prebiotic (Pre), synbiotic (S), cupuassu (C), and probiotic with cupuassu (PC). The viability of probiotic in yogurts (Pro, S, and PC) was evaluated. In addition, instrumental analyses $(\mathrm{pH}$, color, apparent viscosity, and texture) were performed to evaluate the influence of these different ingredients on goat milk yogurts. The probiotic bacteria remained viable $\left(\geq 7 \log \mathrm{cfu} \cdot \mathrm{mL}^{-1}\right)$ throughout the $28 \mathrm{~d}$ of refrigerated storage, which exceeded the minimum count required to confer probiotic physiological benefits. The $\mathrm{pH}$ levels of the yogurts inoculated with L. acidophilus (Pro, S, and PC) were lower than others yogurts (N, Pre, and C). However, all yogurt samples underwent gradual decreases in $\mathrm{pH}$ until 7 to $14 \mathrm{~d}$ of storage. The lightness $\left(L^{*}\right)$ was affected initially by addition of all ingredients (cupuassu pulp, probiotic, and prebiotic). The addition of cupuassu pulp (C and $\mathrm{PC}$ ) increased the $L^{*}$ during the period of storage. Apparent viscosity and firmness decreased in the PC yogurt. The consistency was highest in the yogurts with added prebiotic (Pre and S) than the other yogurts (N, Pro, C, and PC) at the end of the storage period (d 28). The cohesiveness remained constant in all yogurts (N, Pro, Pre, S, C, and $\mathrm{PC})$. Based on the results obtained from the current

Received April 22, 2015.

Accepted June 3, 2015.

${ }^{1}$ Corresponding author: carlosconte@id.uff.br study, it was concluded that cupuassu pulp addition improves the texture of goat milk yogurts. Therefore, this pulp could be an important technological strategy for the dairy goat industry.

Key words: instrumental analysis, Lactobacillus acidophilus LA5, consistency, caprine milk

\section{INTRODUCTION}

Cupuassu (Theobroma grandiflorum) is a tropical fruit native to the Brazilian Amazon. Cupuassu has a high economic potential because of its excellent characteristics such as aroma, flavor, and texture (Faber and Yuyama, 2015). However, because of its distinctive flavor, cupuassu pulp is used as an ingredient in the manufacture of ice cream, juice, liquors, wines, jellies, and other products, such as yogurts, rather than being consumed in natura (Vriesmann and Petkowicz, 2009; Salgado et al., 2013). Cupuassu is a potential source of dietary fiber, mainly soluble fiber (Salgado et al., 2011). The cupuassu pulp has a particular chemical composition, rich in fibers, and contains a considerable amount of starch as well as pectin polysaccharides (Vriesmann et al., 2009), which can provide a different texture than other fruit pulps.

Goat milk is an excellent source of FA, protein, and minerals. When compared with cow milk, goat milk has the following characteristics: (1) less soluble and more insoluble contents of volatile FA, (2) a higher percentage of medium- and short-chain FA, (3) casein micelle with a lower percentage of $\alpha_{S 1}$-casein fraction, (4) smaller size of casein micelle, and (5) more calcium and inorganic phosphorus (Park et al., 2007). Furthermore, the importance of goat milk as a functional food is due to its high digestibility and nutritional value, as well as its therapeutic and dietary characteristics (Park et al., 2007; Fonseca et al., 2013). For these reasons, it is an excellent substitute for cow milk in the nutrition of children and elderly persons (Park et al., 2007; Kapila et al., 2013). Goat milk is widely used for processing fermented milks and other dairy products. Yogurt is the most widely produced and consumed fermented milk and is used as a vehicle for probiotic cultures and 
prebiotics (Costa et al., 2013; Costa and Conte-Junior, 2013). However, compared with cow milk yogurt, it is difficult to make goat milk yogurt with an appropriate flavor (Costa et al., 2014) and consistency, which is mainly due to the difference in casein composition and content ( $\mathrm{Li}$ and Guo, 2006). Micelle structures of goat milk differ from cow milk in average diameter, hydration, and mineralization (Park et al., 2007). Therefore, it is necessary to use certain technological strategies. One alternative is the addition of inulin or another type of fiber, such as that present in fruit pulp (Buriti et al., 2014).

Inulin is one of the most studied and widely used prebiotics, with advantageous technological and nutritional properties (Paseephol et al., 2008). Prebiotics are selectively fermented ingredients that allow specific changes in the composition, activity, or both, of gastrointestinal microbiota, which confers a health benefit on the host (Gibson, 2007). Depending on the concentration, inulin may increase its effect on the structure and texture of dairy products, such as yogurt. Addition of inulin can change the texture and rheological properties of dairy foods (Paseephol et al., 2008).

Probiotics are live microorganisms, which when administered in adequate amounts, may benefit the health of the host (Sanders, 2009). Lactobacillus acidophilus LA-5 strain exhibits viability in milk matrix, such as fermented milks (Costa et al., 2015). However, no reports are present in the literature that this probiotic can improve the texture of goat milk yogurt. Certain strains of Lactobacillus, such as Lactobacillus delbrueckii ssp. bulgaricus, have this ability (Shihata and Shah, 2002).

In this context, the aim of the present study was to improve the texture of goat milk yogurt by adding cupuassu pulp, probiotic, prebiotic, or a combination of these.

\section{MATERIALS AND METHODS}

\section{Goat Milk Yogurts}

Ten liters of goat milk yogurts were produced as described by Costa et al. (2014) with modifications. In all treatments, thermophilic yogurt cultures $(1 \% \mathrm{vol} / \mathrm{vol}$; YF-L903, Chr. Hansen, Valinhos, Brazil) were added in UHT goat whole milk (Cappry's, Rio Grande do Sul, Brazil). A total of 6 treatments were performed: natural $(\mathbf{N})$ containing milk and yogurt cultures; probiotic (Pro) containing milk, yogurt cultures, and probiotic; prebiotic (Pre) containing milk, yogurt cultures, and inulin; synbiotic $(\mathbf{S})$ containing milk, yogurt cultures, probiotic, and inulin; cupuassu (C) containing milk, yogurt cultures, and cupuassu pulp; and probiotic with cupuassu (PC) containing milk, yogurt cultures, probiotic, and cupuassu pulp. For treatments with a probiotic (Pro, S, and PC), L. acidophilus culture (LA-5; Chr. Hansen) was inoculated at a concentration of $5 \%$ (vol/vol) in relation to the total milk volume used to produce the probiotic. For treatments with a prebiotic (Pre and S), 5\% (wt/vol) of inulin (Ingredients \& Systems Biotechnology, São Paulo, SP, Brazil) was added. The inulin polymer has a degree of polymerization from 2 to 50 with an average degree of polymerization of 9 . For the treatments with cupuassu (C and PC), 10\% (wt/vol) pasteurized cupuassu pulp (Polpa de Fruta, Macapá, AP, Brazil) was added.

The yogurt mixtures were fermented in an oven at $43 \pm 2^{\circ} \mathrm{C}$. The fermentation was interrupted when the $\mathrm{pH}$ (AOAC International, 2012) reached 4.5. Finally, the product was packaged in $500-\mathrm{mL}$ plastic pots and stored at $4 \pm 2^{\circ} \mathrm{C}$ for $28 \mathrm{~d}$. The physicochemical analysis and probiotic viability assay were performed during the storage period $(0,7,14,21$, and $28 \mathrm{~d})$. This experiment was repeated 3 times $(\mathrm{n}=3)$, and all analyses were performed in triplicate.

\section{Bacteriological Analysis and Survivability of Probiotic}

Streptococcus thermophilus and Lactobacillus delbrueckii ssp. bulgaricus were analyzed after the yogurt was prepared (d 1) to characterize the fermented product as yogurt. Enumeration of S. thermophilus was performed on M17 agar with lactose, which was incubated under aerobiosis at $37^{\circ} \mathrm{C}$ for $2 \mathrm{~d}$. The count of L. delbrueckii ssp. bulgaricus on de Man, Rogosa and Sharpe (MRS) agar with $\mathrm{pH} 5.4$ was performed after incubation under anaerobiosis at $37^{\circ} \mathrm{C}$ for $3 \mathrm{~d}$ (Codex Alimentarius, 2010). The probiotic (L. acidophilus LA5 ) was counted according to the procedures of Costa et al. (2014), during the storage period $(0,7,14,21$, and $28 \mathrm{~d}$ ). Lactobacillus acidophilus was grown on MRS agar supplemented with $0.15 \%$ (wt/vol) bile salts, and aerobically incubated at $37^{\circ} \mathrm{C}$ for $2 \mathrm{~d}$.

\section{Physicochemical Analysis}

pH Determination. Samples of goat milk yogurts were also analyzed for $\mathrm{pH}$, using a digital $\mathrm{pH}$ meter (model PG1800, Cap Lab, SP, Brazil; AOAC International, 2012).

Instrumental Color. Color determinations were made at $5^{\circ} \mathrm{C}$ by means of a Minolta CM-600D spectrophotometer (Minolta Camera Co., Osaka, Japan). The colorimeter was previously calibrated with illuminant D65 and a $2^{\circ}$ standard observer. Yogurt samples (50 $\mathrm{mL}$ ) at $5^{\circ} \mathrm{C}$ were stirred and placed in an aluminum cyl- 
inder (outside diameter $55 \mathrm{~mm}$ ), with the surface optically flat before measuring, and the sensor was mounted directly on top of the cylinder to prevent ambient light noise. The color space of the yogurts was studied, and the following color coordinates were determined: lightness $\left(\boldsymbol{L}^{*}, 100=\right.$ white, $0=$ black $)$, redness $\left(\boldsymbol{a}^{*}\right.$, +red, -green), and yellowness $\left(\boldsymbol{b}^{*},+\right.$ yellow, -blue). These analyses were performed in triplicate.

\section{Apparent Viscosity and Instrumental Texture Analysis}

The apparent viscosities of the yogurts samples (100 $\mathrm{mL}$ ) were measured at $5^{\circ} \mathrm{C}$ using a Quimis viscometer (Viscosímetro Rotativo Microprocessado, Q860M21, SP, Brazil) equipped with rotor no. 3, mixing at 60 $\mathrm{rpm}$. The apparent viscosity was measured in triplicate.

Texture was assessed using a texture analyzer (TAXT.Plus, Stable Micro Systems Ltd., Surrey, UK) equipped with a 50-kgf load cell, according to Iličić et al. (2014). Texture profile analysis (TPA) was used, analyzing firmness, consistency, and cohesiveness. The samples $(100 \mathrm{~mL})$ were compressed at $10 \%$ of original height with a back extrusion cell (A/BE) disc (diameter $36 \mathrm{~mm}$; distance $30 \mathrm{~mm}$; speed $0.001 / \mathrm{ms}$ ), at a temperature of $4^{\circ} \mathrm{C}$, with 3 measurements per sample averaged for data analysis. The tests were carried out in a standard size back extrusion container $(50 \mathrm{~mm}$ in diameter). The extrusion disc was positioned centrally over the sample container.

\section{Statistical Analysis}

The results for color, $\mathrm{pH}$, apparent viscosity, texture, and L. acidophilus LA-5 were subjected to one-way ANOVA, considering treatments and days as sources of variation. All ANOVA were subjected to Tukey's test at $P<0.05$ using XLSTAT version 2013.2.03 (Addinsoft, Paris, France). The mean bacteria counts were calculated and expressed as $\log _{10} \mathrm{cfu} \cdot \mathrm{g}^{-1}$.

\section{RESULTS AND DISCUSSION}

\section{Bacteriological Analysis}

The counts of S. thermophilus and Lactobacillus delbrueckii ssp. bulgaricus were evaluated to characterize the products made with yogurts, which was analyzed only on d 1 . The yogurts contained, respectively, for $S$. thermophilus and L. delbrueckii ssp. bulgaricus: 11.37 and $7.30(\mathrm{~N}), 11.34$ and $7.62($ Pro), 11.44 and 10.73 (Pre), 9.10 and 7.97 (S), 9.02 and $7.9(\mathrm{C})$, and 11.16 and $11.13(\mathrm{PC}) \log \mathrm{cfu} \cdot \mathrm{g}^{-1}$. Thus, the fermented milks produced in all treatments (N, Pro, Pre, S, C, and PC) were considered to be yogurt, the starter cultures in all the products were higher than $7 \log \mathrm{cfu} \cdot \mathrm{g}^{-1}$ (Codex Alimentarius, 2010).

For the probiotic yogurts, L. acidophilus LA-5 initial values were 11.01, 9.11, and $11.29 \mathrm{log} \mathrm{cfu} \cdot \mathrm{g}^{-1}$ for Pro, S, and $\mathrm{PC}$ yogurts, respectively. In general, the addition of inulin did not influence the probiotic viability (Bedani et al., 2013). However, in our study the treatment with inulin (S) had the lowest initial value of probiotic, which suggests an interference of this ingredient in the development of this microorganism. Figure 1 demonstrates the behavior of the probiotic in all probiotic goat milk treatments. The viability of the probiotic bacteria decreased $(P<0.05)$ in all treatments (Pro, $\mathrm{S}$, and $\mathrm{PC})$ during the first week of storage. The decrease of $L$. acidophilus LA-5 can be explained by 3 mechanisms: the depletion of some nutrients needed by probiotic bacteria; probiotic may have upset the desirable relationship between the yogurt starter culture; and probiotic in the yogurt may have initially produced higher concentrations of antimicrobials such as bacteriocins, $\mathrm{H}_{2} \mathrm{O}_{2}$, or organic acids that may have eventually inhibited more L. acidophilus (Olson and Aryana, 2008).

Thereafter, they were stable, and all probiotic yogurts maintained counts $\geq 7 \mathrm{log} \mathrm{cfu} \cdot \mathrm{g}^{-1}$ during $4 \mathrm{wk}$ (28 d) of storage. Lactobacillus acidophilus LA-5 demonstrated variable viability in the yogurts, with final counts of $9.40,8.02$, and $8.43 \mathrm{log} \mathrm{cfu} \cdot \mathrm{g}^{-1}$ for Pro, $\mathrm{S}$, and PC yogurts, respectively. These counts exceeded the minimum count required to confer probiotic physiological benefits (Bedani et al., 2013; Costa et al., 2013). Regarding the lower viability of the PC yogurts than Pro and S, Kailasapathy et al. (2008) suggested that probiotic strains can be influenced by the $\mathrm{pH}$ of the fruit preparation.

\section{pH Analysis}

The $\mathrm{pH}$ of the goat milk used to produce the yogurts was $6.62 \pm 0.03$. The $\mathrm{pH}$ values of the $\mathrm{N}$, Pro, Pre, S, $\mathrm{C}$, and $\mathrm{PC}$ yogurts are presented in Table 1 . The reduction $(P<0.05)$ of milk $\mathrm{pH}$ after yogurt production (d 0 ), in all treatments, was in line with the growth of the starter culture and the probiotic bacteria. The $\mathrm{pH}$ of all yogurt samples decreased $(P<0.05)$ gradually until 7 to $14 \mathrm{~d}$ of storage, and then increased $(P$ $<0.05)$ in Pre and $\mathrm{C}$ treatments. The high bacterial metabolic activity ferments lactose and produces lactic acid, which decreases the $\mathrm{pH}$ of yogurts (Gaspar et al., 2013). However, when the sugar sources are exhausted, microorganisms begin to consume proteins and start to produce other metabolites, such as biogenic amines (Costa et al., 2015), which increase the pH (Vahedi et al., 2008). This explains the $\mathrm{pH}$ increase of Pre and $\mathrm{C}$ 


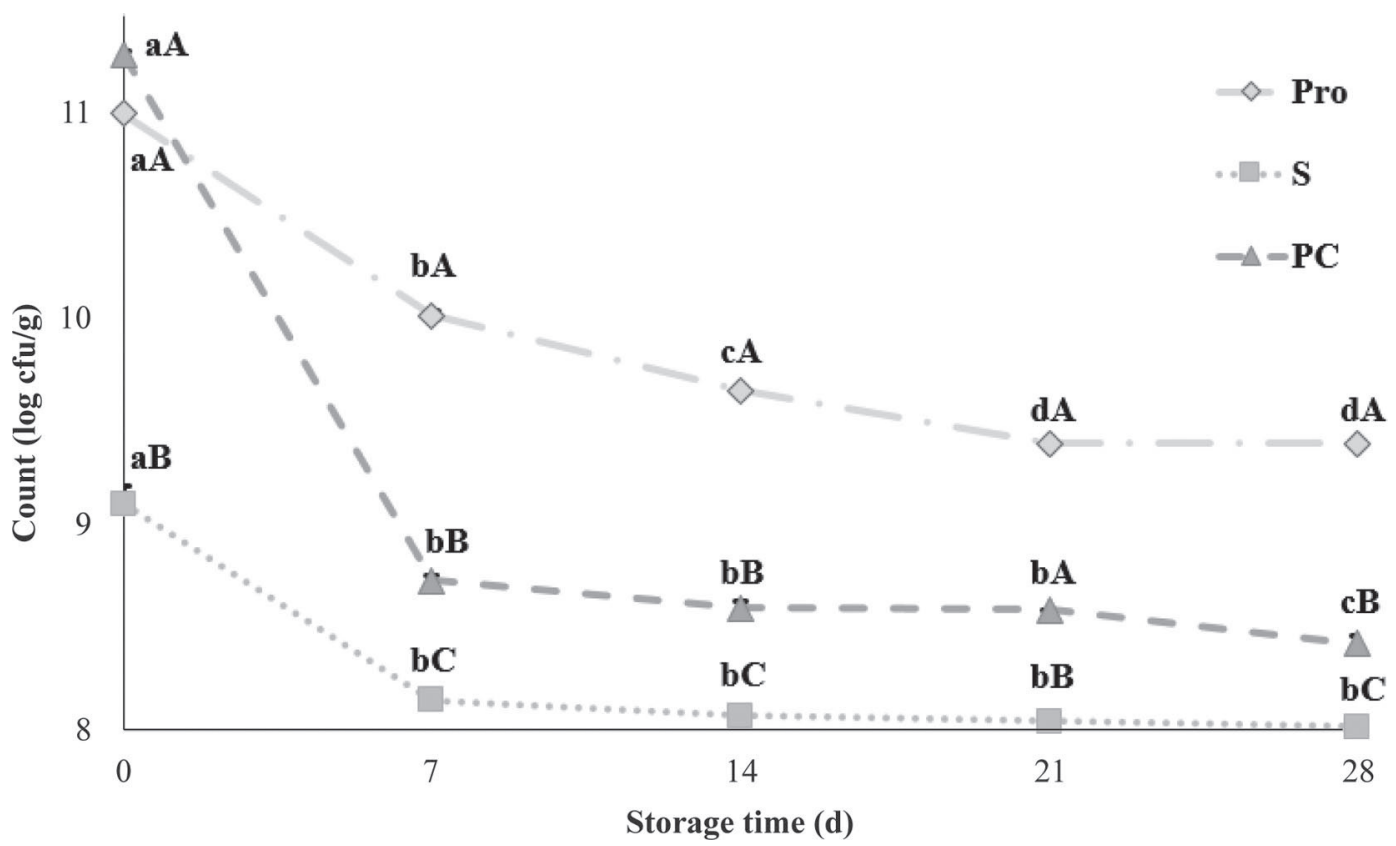

Figure 1. Counts of Lactobacillus acidophilus LA-5 $\left(\log \mathrm{cfu} \cdot \mathrm{g}^{-1}\right)$ in goat milk yogurts with added probiotic (Pro), synbiotic (S) and probiotic with cupuassu (PC) goat milk yogurts during $28 \mathrm{~d}$ of storage. Different uppercase letters (A-C) indicate significant differences among goat milk yogurts, $P<0.05$; different lowercase letters (a-d) indicate significant differences among storage times, $P<0.05$.

yogurts $(P<0.05)$ at the end of the storage period $(21$ and $28 \mathrm{~d})$.

Although all yogurts were cooled at $\mathrm{pH} 4.5$, the $\mathrm{pH}$ levels of the yogurts inoculated with L. acidophilus (Pro, S, and PC) were lower $(P<0.05)$ than the $\mathrm{pH}$ levels of the remaining yogurts $(\mathrm{N}$, Pre, and $\mathrm{C})$ at the end of storage. Espírito Santo et al. (2011) observed similar behavior, and suggested that the occurrence of fatty acid consumption as a carbon source after sugar depletion and fiber pectin degradation to uronic acids could explain the $\mathrm{pH}$ reduction. Moreover, the probiotic bacteria may have produced organic acids (Olson and Aryana, 2008), which contributes to decreasing $\mathrm{pH}$.

\section{Instrumental Color Analysis}

The color parameters $L^{*}, a^{*}$, and $b^{*}$ exhibited some differences $(P<0.05)$, and these changes in color in the 6 goat milk yogurts (N, Pro, Pre, S, C, and PC) stored at $4^{\circ} \mathrm{C}$ for $28 \mathrm{~d}$ are presented in Table 2 .

The $L^{*}$ is lightness, in which 100 represents white, whereas zero represents the black. The $L^{*}$ values were significantly affected by the addition of the cupuassu pulp, probiotic, and prebiotic (Pro, Pre, S, C and PC) on the initial day $(P<0.05)$; however, at the end of the storage period no difference were found between treatments. The $L^{*}$ values in all yogurt (N, Pro, Pre, $\mathrm{S}, \mathrm{C}$, and $\mathrm{PC})$ samples increased $(P<0.05)$ during the $28 \mathrm{~d}$ of storage. The white color of milk results from the presence of colloidal particles, such as milk fat globules and casein micelles, capable of scattering light in the visible spectrum (García-Pérez et al., 2005). In addition, the goat milk has the absence of $\beta$-carotene because of a physiological process of the goats. This substance is converted into vitamin A (Park et al., 2007), which explains the high $L^{*}$ values, mainly in $\mathrm{N}$ yogurt. The goat milk yogurt sample containing cupuassu pulp (C and PC) had a lower $L^{*}$ value than others (N, Pro, Pre, and S). These results suggest that the cupuassu pulp decreased the lightness values of the yogurts, which can be related to this fruit pulp color. Silva and Silva (1999) observed that cupuassu pulp exhibits a light yellow color $\left(L^{*} 70.04, a^{*} 26.36\right.$, and $b^{*}$ 19.73), which consequently can change the yogurt color (C and PC). This difference probably could be well accepted by consumers, as it would reflect the presence of cupuassu. Changes in yogurt color are in agreement with milk substitution, which may be attributed to the different opacity level of gels. This fact increases with the casein proportion and their aggregation level (González-Martınez et al., 2002).

As for the storage period, the $L^{*}$ value increased ( $P$ $<0.05)$ in all treatments (N, Pro, Pre, S, C, PC). Although, the greatest change occurred in Pro, where the $L^{*}$ value increased from 89.24 to 92.39 . As the result of Pre and S, some studies achieved the same effect, which demonstrated that inulin increase $L^{*}$ value (Noziere et al., 2006; Villegas et al., 2010). However, this result dif- 
Table 1. $\mathrm{pH}$ values (means \pm standard deviation) of goat milk yogurts measured during the storage period at $4^{\circ} \mathrm{C}$

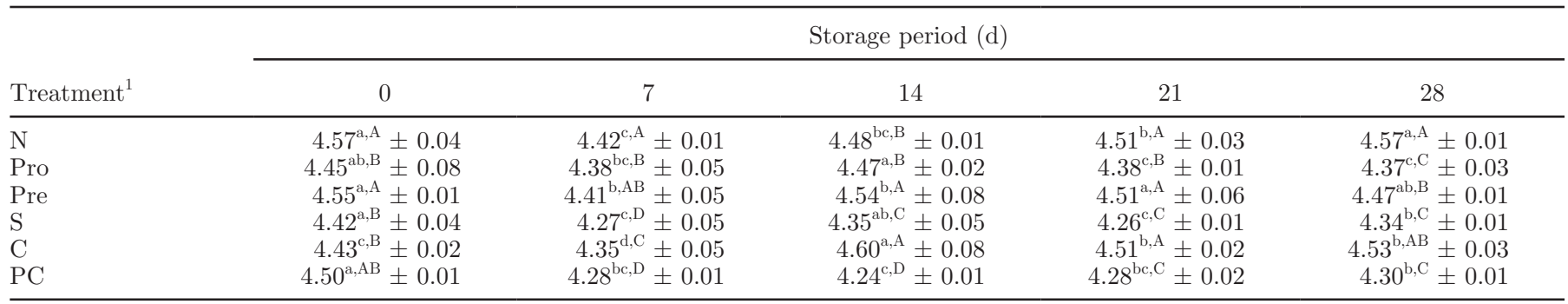

${ }^{\mathrm{a}-\mathrm{d}}$ Different lowercase superscripts indicate significant differences among storage times, $P<0.05$.

${ }^{\mathrm{A}-\mathrm{D}}$ Different uppercase superscripts indicate significant differences among goat milk yogurts, $P<0.05$.

${ }^{1} \mathrm{~N}=$ natural; Pro = probiotic; Pre = prebiotic; $\mathrm{S}=$ synbiotic; $\mathrm{C}=$ cupuassu; $\mathrm{PC}=$ probiotic with cupuassu.

fers from those found by Mani-López et al. (2014), who observed no changes in color parameters during storage. This difference may related to distinct factors such as the probiotic strain (L. acidophilus, Lactobacillus casei, and Lactobacillus reuteri), the absence of inulin, and the type of milk (cow milk), which depending on combination of the ingredients could generate a unique color profile (Mani-López et al., 2014).

Regarding $a^{*}$ (greenness-redness) initial values, treatments added with prebiotic (Pre and $\mathrm{S}$ ) and cupuassu pulp $(\mathrm{C}$ and $\mathrm{PC})$ differed from control $(P<$ $0.05)$. However, Pre and S had lower values, whereas $\mathrm{C}$ and PC had higher values. Kim et al. (2011) reported the same behavior of Pre and S treatments, which can be explained by the addition of inulin that increases the water-holding capacity. In all treatments (N, Pro, Pre, $\mathrm{S}, \mathrm{C}$, and PC), during storage, an increase of $a^{*}$ values was observed $(P<0.05)$, indicating an increase in the redness of the yogurts. Estrada et al. (2011) explained this increase through the gel stirring and acidity changes in yogurt during refrigerated storage, because they may cause changes in tissue structure that result in leakage of natural pigments, such as carotenoids, to the yogurt matrix.

The $b^{*}$ (blueness-yellowness) values was different between all treatments, and the $\mathrm{N}$ treatment was less yellow than the other treatments (Pro, Pre, S, C, and $\mathrm{PC})$. The greater yellowness $(P<0.05)$ of Pro, Pre, S, $\mathrm{C}$, and $\mathrm{PC}$ can be attributed to the addition of cupuassu pulp, and probiotic and prebiotic ingredients, which all differed from N. Yellowness of the yogurt depends on the type and level of fruit or fiber. Similar results were described for yogurts fortified with commercial apple fiber (Staffolo et al., 2004), orange fiber (García-Pérez

Table 2. The color values (means \pm standard deviation) of goat milk yogurt measured at $4^{\circ} \mathrm{C}$ during the storage period

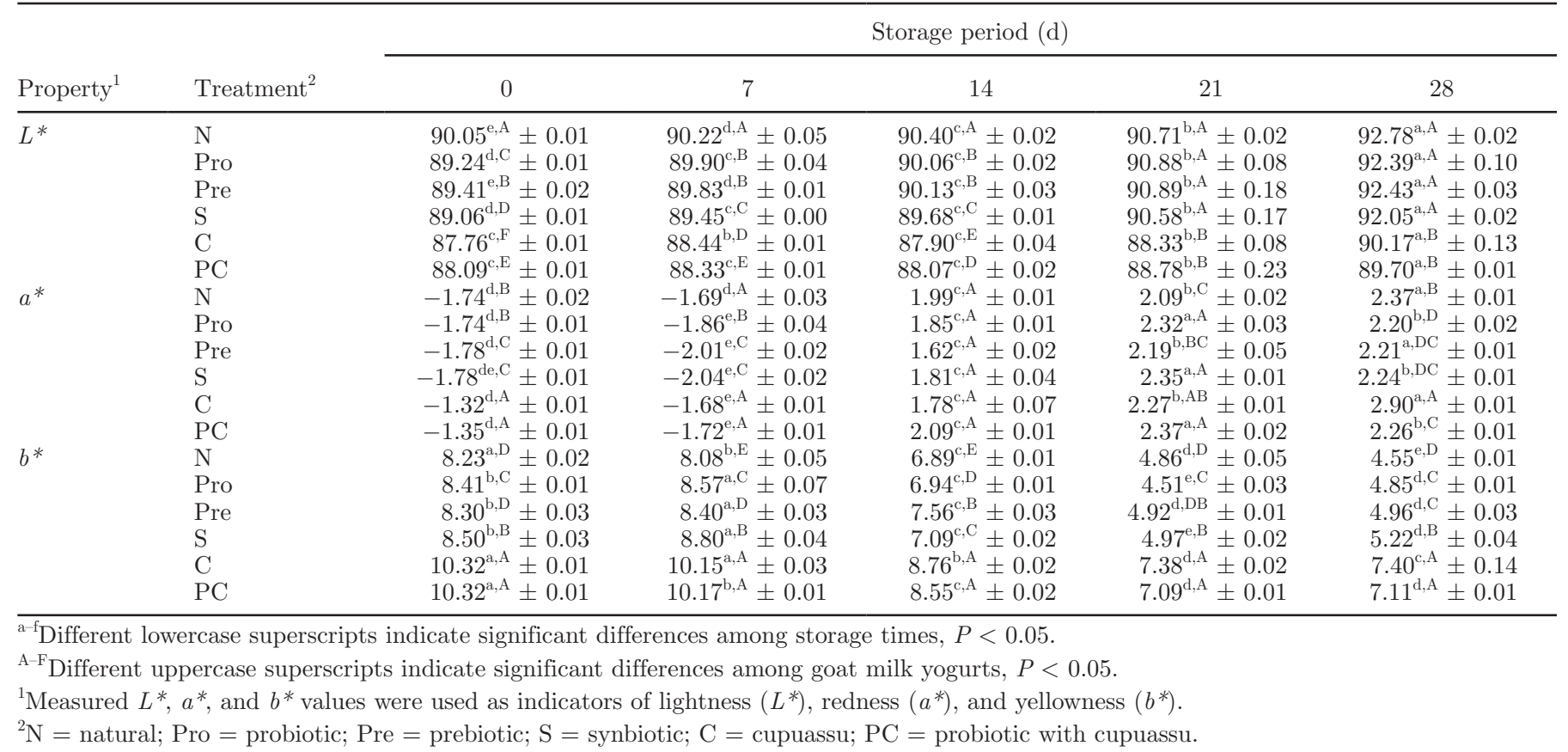


et al., 2005), and wheat bran (Hashim et al., 2009). The $b^{*}$ values decreased significantly in all yogurts $(\mathrm{N}$, Pro, Pre, S, C, and PC) during the $28 \mathrm{~d}$ of refrigerated storage $(P<0.05)$.

These results (increased $a^{*}$ and decreased $b^{*}$ ) indicate that the reddish color was reinforced, which should be attributed to the goat milk, due to carotenoids (Noziere et al., 2006) and lipid oxidation (Xia et al., 2012), because all the yogurts exhibited the same behavior. Statistical analyses demonstrated that, although the pattern was the same, the treatments with and without cupuassu pulp differed $(P<0.05)$. Other studies have presented the same performance (increased $a^{*}$ and decreased $b^{*}$ ) when fruit (pomegranate) and vegetal (yam) ingredients were added to yogurt (Kim et al., 2011; Trigueros et al., 2014).

\section{Apparent Viscosity Analysis}

The effects of addition of a probiotic, a prebiotic, and cupuassu pulp on the apparent viscosity of the goat milk yogurts (N, Pro, Pre, S, C, and PC) during storage are presented in Figure 2. On the initial day, the viscosities of the Pre, S, C, and PC yogurts were higher than $\mathrm{N}$ goat milk $(P<0.05$; i.e., the addition of cupuassu pulp and inulin increased the apparent viscosity). The addition of inulin may increase the structure of dairy products, which can change the viscosity and rheological properties of dairy foods. Also, it can be technologically used as a fat substitute (Paseephol et al., 2008). The cupuassu pulp has a particular chemical composition, being rich in fiber (mainly soluble fiber) and containing a considerable amount of starch as well as pectin polysaccharides (Vriesmann et al., 2009), which could improve the apparent viscosity of $\mathrm{C}$ and PC yogurts.

Regarding the period of storage, the apparent viscosity remained constant until d 7 of storage, in all goat milk yogurts, and then decreased $(P<0.05)$. The decrease in apparent viscosity might have been caused by the whey separation with increasing storage time (Al Mijan et al., 2014). This behavior is in agreement with the results of Wang et al. (2012), who compared the apparent viscosity of goat and cow milk yogurts.

The development of apparent viscosity in yogurts is associated with the aggregation of casein micelles and gel formation, which is a consequence of biochemical and physicochemical changes during fermentation of milk (Gaygadzhiev et al., 2009; Singh and Kim, 2009). The apparent viscosity also increases as the $\mathrm{pH}$ of

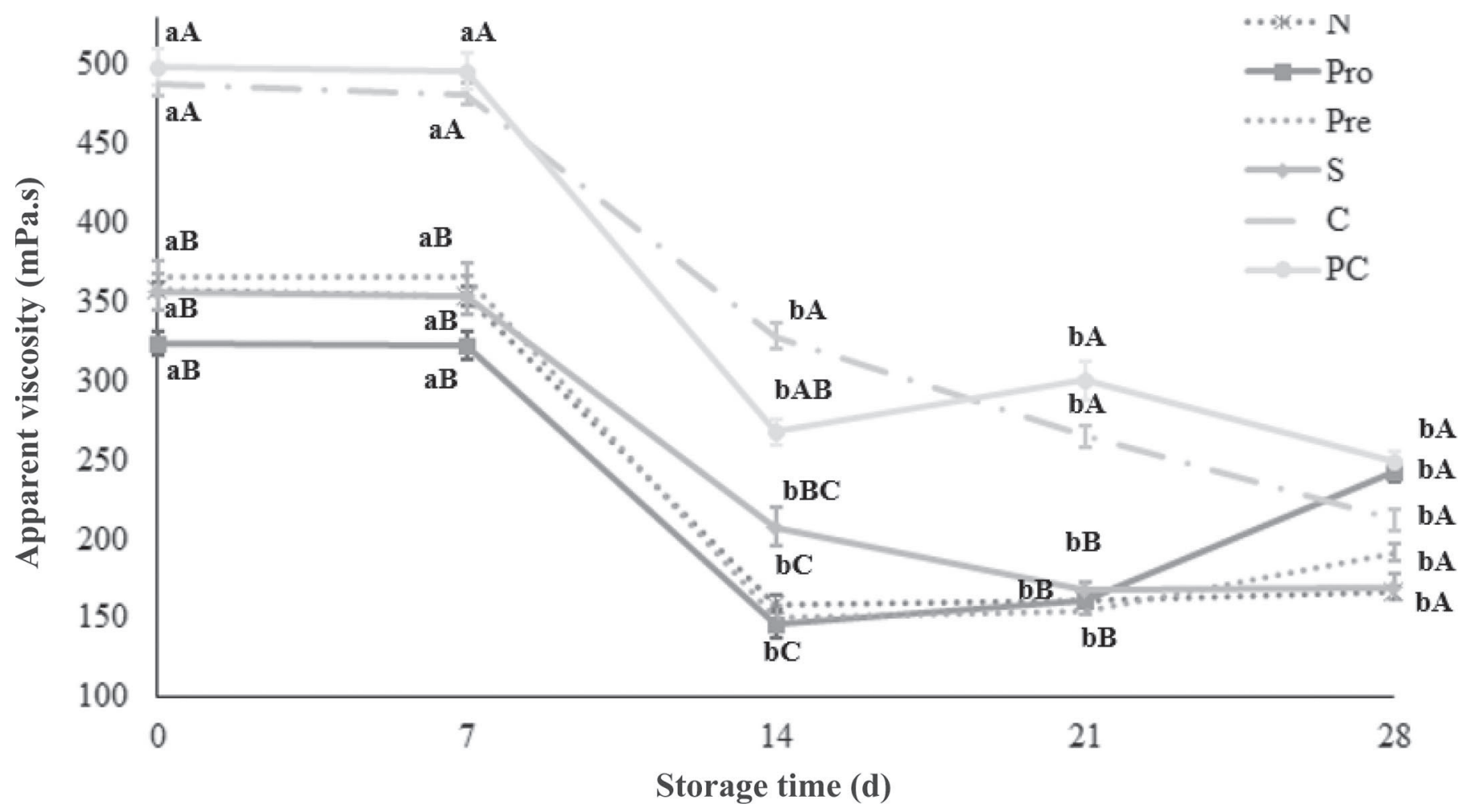

Figure 2. Apparent viscosity of the natural (N), probiotic (Pro), prebiotic (Pre), synbiotic (S), cupuassu (C), and probiotic with cupuassu (PC) goat milk yogurts during 28 d of refrigerated storage. Different uppercase letters $(\mathrm{A}-\mathrm{C})$ indicate significant differences among goat milk yogurts, $P<0.05$; different lowercase letters $(\mathrm{a}, \mathrm{b})$ indicate significant differences among storage times, $P<0.05$. 
Table 3. Firmness, consistency, and cohesiveness values (means \pm standard deviation) of goat milk yogurts measured at $4^{\circ} \mathrm{C}$ during the storage period

\begin{tabular}{|c|c|c|c|c|c|c|}
\hline $\mathrm{TPA}^{1}$ parameter & Treatment $^{2}$ & \multicolumn{5}{|c|}{ Storage period (d) } \\
\hline \multirow[t]{5}{*}{ Firmness (g) } & $\mathrm{N}$ & $22.28^{\mathrm{a}, \mathrm{B}} \pm 0.12$ & $21.42^{\mathrm{a}, \mathrm{A}} \pm 0.20$ & $20.81^{\mathrm{a}, \mathrm{A}} \pm 0.13$ & $21.27^{\mathrm{a}, \mathrm{A}} \pm 0.18$ & $20.70^{\mathrm{a}, \mathrm{AB}} \pm 0.11$ \\
\hline & Pro & $22.32^{\mathrm{a}, \mathrm{B}} \pm 0.11$ & $21.85^{\mathrm{a}, \mathrm{A}} \pm 0.06$ & $20.52^{\mathrm{ab}, \mathrm{A}} \pm 0.28$ & $19.30^{\mathrm{ab}, \mathrm{A}} \pm 0.62$ & $17.57^{\mathrm{b}, \mathrm{B}} \pm 0.12$ \\
\hline & Pre & $21.92^{\mathrm{a}, \mathrm{B}} \pm 0.21$ & $22.81^{\mathrm{a}, \mathrm{A}} \pm 0.47$ & $21.41^{\mathrm{a}, \mathrm{A}} \pm 0.17$ & $21.17^{\mathrm{a}, \mathrm{A}} \pm 0.14$ & $21.45^{\mathrm{a}, \mathrm{A}} \pm 0.32$ \\
\hline & S & $22.14^{\mathrm{b}, \mathrm{A}} \pm 0.16$ & $21.59^{\mathrm{a}, \mathrm{A}} \pm 0.11$ & $20.52^{\mathrm{a}, \mathrm{A}} \pm 0.28$ & $21.59^{\mathrm{a}, \mathrm{A}} \pm 0.31$ & $20.16^{\mathrm{a}, \mathrm{AB}} \pm 0.02$ \\
\hline & $\mathrm{C}$ & $21.85^{\mathrm{ab}} \pm 0.23$ & $21.88^{\mathrm{a}, \mathrm{A}} \pm 0.02$ & $21.78^{\mathrm{a}, \mathrm{A}} \pm 0.35$ & $20.88^{\mathrm{a}, \mathrm{A}} \pm 0.02$ & $20.73^{\mathrm{a}, \mathrm{AB}} \pm 0.12$ \\
\hline \multirow{5}{*}{ Consistency (g/s) } & Pro & $126.92^{\mathrm{a}, \mathrm{B}} \pm 0.13$ & $121.77^{\mathrm{a}, \mathrm{A}} \pm 0.20$ & $118.69^{\mathrm{ab}, \mathrm{B}} \pm 0.17$ & $103.22^{\mathrm{b}, \mathrm{A}} \pm 0.19$ & $98.07^{\mathrm{b}, \mathrm{B}} \pm 0.16$ \\
\hline & Pre & $121.31^{\mathrm{a}, \mathrm{AB}} \pm 0.44$ & $126.43^{\mathrm{a}, \mathrm{A}} \pm 0.30$ & $125.98^{\mathrm{a}, \mathrm{AB}} \pm 0.32$ & $127.23^{\mathrm{a}, \mathrm{A}} \pm 0.05$ & $127.30^{\mathrm{a}, \mathrm{A}} \pm 0.31$ \\
\hline & $\mathrm{S}$ & $120.12^{\mathrm{a}, \mathrm{AB}} \pm 0.29$ & $117.63^{\mathrm{a}, \mathrm{A}} \pm 0.16$ & $115.34^{\mathrm{a}, \mathrm{B}} \pm 0.43$ & $113.96^{\mathrm{a}, \mathrm{A}} \pm 0.06$ & $123.13^{\mathrm{a}, \mathrm{A}} \pm 0.06$ \\
\hline & $\mathrm{C}$ & $122.09^{\mathrm{a}, \mathrm{AB}} \pm 0.12$ & $122.18^{\mathrm{a}, \mathrm{A}} \pm 0.05$ & $124.25^{\mathrm{a}, \mathrm{A}} \pm 0.21$ & $123.55^{\mathrm{a}, \mathrm{A}} \pm 0.10$ & $122.46^{\mathrm{a}, \mathrm{B}} \pm 0.20$ \\
\hline & $\mathrm{PC}$ & $127.29^{\mathrm{a}, \mathrm{A}} \pm 0.67$ & $122.46^{\mathrm{a}, \mathrm{A}} \pm 0.31$ & $120.56^{\mathrm{a}, \mathrm{B}} \pm 0.04$ & $120.25^{\mathrm{a}, \mathrm{A}} \pm 0.11$ & $122.6^{\mathrm{a}, \mathrm{B}} \pm 0.14$ \\
\hline \multirow[t]{2}{*}{ Cohesiveness (g) } & $\mathrm{N}$ & $-30.29^{\mathrm{a}, \mathrm{AB}} \pm 0.16$ & $-31.48^{\mathrm{a}, \mathrm{A}} \pm 0.32$ & $-30.54^{\mathrm{a}, \mathrm{A}} \pm 0.25$ & $-30.72^{\mathrm{a}, \mathrm{A}} \pm 0.55$ & $-30.97^{\mathrm{a}, \mathrm{A}} \pm 0.05$ \\
\hline & Pro & $-32.45^{\mathrm{a}, \mathrm{B}} \pm 0.65$ & $-30.29^{\mathrm{a}, \mathrm{A}} \pm 0.11$ & $-31.55^{\mathrm{a}, \mathrm{A}} \pm 0.10$ & $-29.75^{\mathrm{a}, \mathrm{A}} \pm 0.48$ & $-29.83^{\mathrm{a}, \mathrm{A}} \pm 0.04$ \\
\hline
\end{tabular}

$\overline{\mathrm{a}, \mathrm{b}}$ Different lowercase superscripts indicate significant differences among storage times, $P<0.05$.

${ }^{\mathrm{A}, \mathrm{B}}$ Different uppercase superscripts indicate significant differences among goat milk yogurts, $P<0.05$.

${ }^{1} \mathrm{TPA}=$ texture profile analysis.

${ }^{2} \mathrm{~N}=$ natural; Pro = probiotic; Pre = prebiotic; $\mathrm{S}=$ synbiotic; $\mathrm{C}=$ cupuassu; $\mathrm{PC}=$ probiotic with cupuassu.

milk decreases, which is attributable to the additional swelling of casein micelles. At pH 5.4 to 5.3, the initial increase of apparent viscosity can be observed, at this stage indicating the initiation of aggregation. In the $\mathrm{pH}$ range of 5.1 to 4.6 , the apparent viscosity of goat products increases (Park, 2007), which typically occurs in yogurts. In our study, this increase on apparent viscosity effect by $\mathrm{pH}$ happened in all treatments (N, Pro, Pre, S, C, and PC).

However, the casein micelles of goat milk contain more calcium, inorganic phosphorus, and noncentrifugal casein, and are less solvated, less heat stable, and lose $\beta$-casein more readily than bovine casein micelles (Park et al., 2007). This fact is related to the large difference in the apparent viscosity of yogurt made with goat milk compared with cow milk.

\section{Instrumental Texture Analysis}

The TPA parameters well represented the yogurt textural characteristics. Firmness, consistency, and cohesiveness are commonly evaluated in determining yogurt texture (Espírito Santo et al., 2012; Buriti et al., 2014; Iličić et al., 2014). Different goat milk yogurts were measured, as presented in Table 3.

Gel formation is one of the main texture properties of yogurt. This structure is result of casein aggregation by $\mathrm{pH}$ decreasing and disulfide bonding between $\kappa$-casein and denatured whey proteins (Damin et al., 2009). In addition, other parameters, such as milk base compo- sition, heat treatment applied, fermentation process, storage conditions, and starter culture, also perform a determinative role in gel structure formation (Akalın et al., 2012).

Regarding firmness, no statistical difference $(P>$ 0.05 ) was found between the treatments. The firmness decreased in all yogurts (N, Pro, Pre, S, C, and PC) during $28 \mathrm{~d}$ of storage (Table 3). However, despite similar behavior in the different treatments, this decline was statistically significant $(P<0.05)$ only in the PC yogurt. Therefore, the addition of each ingredient (cupuassu pulp and probiotic) separately did not affect the firmness, although together, they changed this parameter. Oliveira et al. (2001) reported that the firmness of fermented milks is highly dependent on the culture composition, TS, and protein content of the product. Moreover, the type of protein and the interaction between the ingredients used and the composition of the culture can affect the firmness of the product (Oliveira et al., 2001). This fact may explain the significant decline in the yogurt PC, which has lower lactic protein content when compared with other treatments. The firmness of yogurts is also related to the bacteria L. delbrueckii ssp. bulgaricus. The incorporation of this microorganism into the yogurt starter culture improved the firmness, which in general is due to the attachment of mucogenic strains to the protein matrix via the exopolysaccharides (Shihata and Shah, 2002).

The consistency of the samples was significantly high $(P<0.05)$ in the yogurts with added prebiotic (Pre and 
S) compared with the others (N, Pro, C, and PC) at the end of storage (d 28). Furthermore, the consistency of the Pre and S goat milk yogurt remained constant $(P$ $>0.05$ ) during the storage period (Table 3 ). A similar result was obtained for the yogurt consistency with the addition of the inulin (Pimentel et al., 2012, 2013). This prebiotic helped to increase this physical property, but up to a certain concentration. The interactions between whey proteins and $\kappa$-casein make the micelles less sensitive to the $\mathrm{pH}$ decline, increasing their solubility. Inulin is a soluble fiber and a water-structuring agent. In addition, this prebiotic can form complexes with the protein aggregates, and it must be part of the structural network that is formed during fermentation and structuring of the stirred yogurt (Srisuvor et al., 2013).

The cohesiveness values indicated that the predominance of protein in the composition of the yogurt caused the large number of casein-casein linkages broken during stress application to reform after the stress was released (Peng et al., 2009). The cohesiveness values are provided in Table 3. In this study, the cohesiveness in all treatments remained constant $(P>0.05)$ during refrigeration storage. Therefore, the addition of the cupuassu pulp, probiotic, and prebiotic did not affect the cohesiveness. Hence, cohesiveness should not be considered a good parameter because all treatments showed the same results. The cohesiveness value together with the springiness may indicate a predominance of protein in the composition of the yogurt, which led to a large promoted number of broken casein-casein linkages during stress application, which reformed after the stress was released (Sandoval-Castilla et al., 2004). A possible explanation for the similar behavior of this parameter in all yogurts is that they have a proximate milk protein content.

\section{CONCLUSIONS}

We conclude that cupuassu pulp is potentially useful in the manufacture of goat milk yogurts to improve their texture. In this way, cupuassu is an important technological strategy for the dairy goat industry.

\section{ACKNOWLEDGMENTS}

The authors thank the Fundação de Amparo à Pesquisa do Estado do Rio de Janeiro (grant no. E-26/201.185/2014, FAPERJ, Brazil) and the Conselho Nacional de Desenvolvimento Científico e Tecnológico (grant no. 311361/2013-7, CNPq, Brazil) for financial support. M. P. Costa was supported by the Conselho Nacional de Desenvolvimento Cientifico e Tecnológico $(\mathrm{CNPq})$.

\section{REFERENCES}

Akalın, A. S., G. Unal, N. Dinkci, and A. A. Hayaloglu. 2012. Microstructural, textural, and sensory characteristics of probiotic yogurts fortified with sodium calcium caseinate or whey protein concentrate. J. Dairy Sci. 95:3617-3628. http://dx.doi.org/10.3168/ jds.2011-5297.

Al Mijan, M., K.-H. Choi, and H.-S. Kwak. 2014. Physicochemical, microbial, and sensory properties of nanopowdered eggshell-supplemented yogurt during storage. J. Dairy Sci. 97:3273-3280.

AOAC International. 2012. Official Methods of Analysis. 19th ed. AOAC Int., Arlington, VA.

Bedani, R., E. A. Rossi, and S. M. Isay Saad. 2013. Impact of inulin and okara on Lactobacillus acidophilus La-5 and Bifidobacterium animalis $\mathrm{Bb}-12$ viability in a fermented soy product and probiotic survival under in vitro simulated gastrointestinal conditions. Food Microbiol.

Buriti, F. C. A., S. C. Freitas, A. S. Egito, and K. M. O. dos Santos. 2014. Effects of tropical fruit pulps and partially hydrolysed galactomannan from Caesalpinia pulcherrima seeds on the dietary fibre content, probiotic viability, texture and sensory features of goat dairy beverages. LWT Food Sci. Technol. (Campinas.) 59:196203. http://dx.doi.org/10.1016/j.lwt.2014.04.022.

Codex Alimentarius. 2010. Codex standard for fermented milks. 2nd ed. Codex standard 243-2003 in Codex Alimentarius: Milk and Milk Products. Codex Alimentarius Commission, Brussels, Belgium

Costa, M. P., C. F. Balthazar, R. M. Franco, E. T. Mársico, A. G Cruz, and C. A. Conte. 2014. Changes on expected taste perception of probiotic and conventional yogurts made from goat milk after rapidly repeated exposure. J. Dairy Sci. 97:2610-2618. http:// dx.doi.org/10.3168/jds.2013-7617.

Costa, M. P., C. F. Balthazar, B. L. Rodrigues, C. A. Lazaro, A. C. Silva, A. G. Cruz, and C. A. Conte Junior. 2015. Determination of biogenic amines by high-performance liquid chromatography (HPLC-DAD) in probiotic cow's and goat's fermented milks and acceptance. Food Sci. Nutr. http://dx.doi.org/10.1002/fsn3.200.

Costa, M. P., and C. A. Conte-Junior. 2013. Leites fermentados como alimentos funcionais. Anim. Business Brasil 3:60-65.

Costa, M. P. C. F. Balthazar, R. V. de B. Pinto, A. G. Cruz, and C. A. Conte Júnior. 2013. Leite fermentado: Potencial alimento funcional. Encicl. Biosf. 9:1387-1408.

Damin, M. R., M. R. Alcântara, A. P. Nunes, and M. N. Oliveira 2009. Effects of milk supplementation with skim milk powder, whey protein concentrate and sodium caseinate on acidification kinetics, rheological properties and structure of nonfat stirred yogurt. LWT Food Sci. Technol. (Campinas.) 42:1744-1750. http:// dx.doi.org/10.1016/j.lwt.2009.03.019.

Espírito Santo, A. P. P. Perego, A. Converti, and M. N. Oliveira. 2011. Influence of food matrices on probiotic viability - A review focusing on the fruity bases. Trends Food Sci. Technol. 22:377385. http://dx.doi.org/10.1016/j.tifs.2011.04.008.

Espírito Santo, A. P., P. Perego, A. Converti, and M. N. Oliveira 2012. Influence of milk type and addition of passion fruit peel powder on fermentation kinetics, texture profile and bacterial viability in probiotic yoghurts. LWT Food Sci. Technol. (Campinas.) 47:393-399. http://dx.doi.org/10.1016/j.lwt.2012.01.038.

Estrada, J. D., C. Boeneke, P. Bechtel, and S. Sathivel. 2011. Developing a strawberry yogurt fortified with marine fish oil. J. Dairy Sci. 94:5760-5769

Faber, M. A., and L. K. O. Yuyama. 2015. Nectar mix functional based on Amazonian fruits. J. Cell Sci. Ther. 6:197. http://dx.doi. org/10.4172/2157-7013.1000197.

Fonseca, C. R., K. Bordin, A. M. Fernandes, C. E. C. Rodrigues, C. H. Corassin, A. G. Cruz, and C. A. F. Oliveira. 2013. Storage of refrigerated raw goat milk affecting the quality of whole milk powder. J. Dairy Sci. 96:4716-4724.

García-Pérez, F. J., Y. Lario, J. Fernández-López, E. Sayas, J. A. Pérez-Alvarez, and E. Sendra. 2005. Effect of orange fiber addition on yogurt color during fermentation and cold storage. Color Res. Appl. 30:457-463 
Gaspar, P., A. L. Carvalho, S. Vinga, H. Santos, and A. R. Neves. 2013. From physiology to systems metabolic engineering for the production of biochemicals by lactic acid bacteria. Biotechnol. Adv. 31:764-788.

Gaygadzhiev, Z., M. Corredig, and M. Alexander. 2009. The impact of the concentration of casein micelles and whey protein-stabilized fat globules on the rennet-induced gelation of milk. Colloids Surf. B Biointerfaces 68:154-162.

Gibson, G. R. 2007. Functional foods: Probiotics and prebiotics. Culture (Que.) 28:965-989.

González-Martınez, C., M. Becerra, M. Cháfer, A. Albors, J. M. Carot, and A. Chiralt. 2002. Influence of substituting milk powder for whey powder on yoghurt quality. Trends Food Sci. Technol. 13:334-340.

Hashim, I. B., A. H. Khalil, and H. S. Afifi. 2009. Quality characteristics and consumer acceptance of yogurt fortified with date fiber. J. Dairy Sci. 92:5403-5407.

Iličić, M. D., S. D. Milanović, M. Đ. Carić, L. P. Dokić, and K. G. Kanurić. 2014. Effect of transglutaminase on texture and flow properties of stirred probiotic yoghurt during storage. J. Texture Stud. 45:13-19.

Kailasapathy, K., I. Harmstorf, and M. Phillips. 2008. Survival of Lactobacillus acidophilus and Bifidobacterium animalis ssp. lactis in stirred fruit yogurts. LWT Food Sci. Technol. (Campinas.) 41:1317-1322.

Kapila, R., P. K. Kavadi, and S. Kapila. 2013. Comparative evaluation of allergic sensitization to milk proteins of cow, buffalo and goat. Small Rumin. Res. 112:191-198. http://dx.doi.org/10.1016/j. smallrumres.2012.11.028.

Kim, S. H., S. Y. Lee, G. Palanivel, and H. S. Kwak. 2011. Effect of Dioscorea opposita Thunb. (yam) supplementation on physicochemical and sensory characteristics of yogurt. J. Dairy Sci. 94:1705-1712.

Li, J., and M. Guo. 2006. Effects of polymerized whey proteins on consistency and water-holding properties of goat's milk yogurt. J. Food Sci. 71:C34-C38.

Mani-López, E., E. Palou, and A. López-Malo. 2014. Probiotic viability and storage stability of yogurts and fermented milks prepared with several mixtures of lactic acid bacteria. J. Dairy Sci. 97:2578-2590. http://dx.doi.org/10.3168/jds.2013-7551.

Noziere, P., B. Graulet, A. Lucas, B. Martin, P. Grolier, and M. Doreau. 2006. Carotenoids for ruminants: From forages to dairy products. Anim. Feed Sci. Technol. 131:418-450.

Oliveira, M. N., I. Sodini, F. Remeuf, and G. Corrieu. 2001. Effect of milk supplementation and culture composition on acidification, textural properties and microbiological stability of fermented milks containing probiotic bacteria. Int. Dairy J. 11:935-942. http:// dx.doi.org/10.1016/S0958-6946(01)00142-X.

Olson, D. W., and K. J. Aryana. 2008. An excessively high Lactobacillus acidophilus inoculation level in yogurt lowers product quality during storage. LWT Food Sci. Technol. (Campinas.) 41:911-918.

Park, Y. W. 2007. Rheological characteristics of goat and sheep milk. Small Rumin. Res. 68:73-87. http://dx.doi.org/10.1016/j. smallrumres.2006.09.015.

Park, Y. W., M. Juárez, M. Ramos, and G. F. W. Haenlein. 2007. Physico-chemical characteristics of goat and sheep milk. Small Rumin. Res. 68:88-113. http://dx.doi.org/10.1016/j. smallrumres.2006.09.013.

Paseephol, T., D. M. Small, and F. Sherkat. 2008. Rheology and texture of set yogurt as affected by inulin addition. J. Texture Stud. 39:617-634.

Peng, Y., M. Serra, D. S. Horne, and J. A. Lucey. 2009. Effect of fortification with various types of milk proteins on the rheological properties and permeability of nonfat set yogurt. J. Food Sci. 74:C666-C673.

Pimentel, T. C., A. G. Cruz, and S. H. Prudencio. 2013. Short communication: Influence of long-chain inulin and Lactobacillus para- casei subspecies paracasei on the sensory profile and acceptance of a traditional yogurt. J. Dairy Sci. 96:6233-6241. http://dx.doi. org/10.3168/jds.2013-6695.

Pimentel, T. C., S. Garcia, and S. H. Prudencio. 2012. Effect of longchain inulin on the texture profile and survival of Lactobacillus paracasei ssp. paracase $i$ in set yoghurts during refrigerated storage. Int. J. Dairy Technol. 65:104-110. http://dx.doi.org/10.1111/ j.1471-0307.2011.00739.x.

Salgado, H., L. Lourenço, C. Sousa, and E. Araújo. 2013. Dessert made from Cupuassu fruit on Eastern Amazon: Preparation and shelf life. J. Food Process. Preserv. 37:391-398. http://dx.doi. org/10.1111/j.1745-4549.2011.00658.x.

Salgado, J. M., B. S. Rodrigues, C. M. Donado-Pestana, C. T. dos S. Dias, and M. C. Morzelle. 2011. Cupuassu (Theobroma grandiflorum) peel as potential source of dietary fiber and phytochemicals in whole-bread preparations. Plant Foods Hum. Nutr. 66:384390. http://dx.doi.org/10.1007/s11130-011-0254-0.

Sanders, M. E. 2009. How do we know when something called "probiotic" is really a probiotic? A guideline for consumers and health care professionals. Funct. Food Rev. 1:3-12

Sandoval-Castilla, O., C. Lobato-Calleros, E. Aguirre-Mandujano, and E. J. Vernon-Carter. 2004. Microstructure and texture of yogurt as influenced by fat replacers. Int. Dairy J. 14:151-159.

Shihata, A., and N. P. Shah. 2002. Influence of addition of proteolytic strains of Lactobacillus delbrueckii ssp. bulgaricus to commercial ABT starter cultures on texture of yoghurt, exopolysaccharide production and survival of bacteria. Int. Dairy J. 12:765-772.

Silva, F. M., and C. L. M. Silva. 1999. Colour changes in thermally processed cupuaçu (Theobroma grandiflorum) puree: Critical times and kinetics modelling. Int. J. Food Sci. Technol. 34:87-94. http://dx.doi.org/10.1046/j.1365-2621.1999.00246.x.

Singh, M., and S. Kim. 2009. Yogurt fermentation in the presence of starch-lipid composite. J. Food Sci. 74:C85-C89.

Srisuvor, N., N. Chinprahast, C. Prakitchaiwattana, and S. Subhimaros. 2013. Effects of inulin and polydextrose on physicochemical and sensory properties of low-fat set yoghurt with probioticcultured banana purée. LWT Food Sci. Technol. (Campinas.) $51: 30-36$

Staffolo, M. D., N. Bertola, M. Martino, and Y. A. Bevilacquaa. 2004. Influence of dietary fiber addition on sensory and rheological properties of yogurt. Int. Dairy J. 14:263-268.

Trigueros, L., A. Wojdylo, and E. Sendra. 2014. Antioxidant activity and protein-polyphenol interactions in a pomegranate (Punica granatum L.) yogurt. J. Agric. Food Chem. 62:6417-6425.

Vahedi, N., M. M. Tehrani, and F. Shahidi. 2008. Optimizing of fruit yoghurt formulation and evaluating its quality during storage. Am. Euras. J. Agric. Environ. Sci. 3:922-927.

Villegas, B., A. Tárrega, I. Carbonell, and E. Costell. 2010. Optimising acceptability of new prebiotic low-fat milk beverages. Food Qual. Prefer. 21:234-242.

Vriesmann, L. C., and C. L. Petkowicz. 2009. Polysaccharides from the pulp of cupuassu (Theobroma grandiflorum): Structural characterization of a pectic fraction. Carbohydr. Polym. 77:72-79.

Vriesmann, L. C., J. L. M. Silveira, and C. L. de O. Petkowicz. 2009. Chemical and rheological properties of a starch-rich fraction from the pulp of the fruit cupuassu (Theobroma grandiflorum). Mater. Sci. Eng. C 29:651-656. http://dx.doi.org/10.1016/j. msec.2008.12.011

Wang, W., Y. Bao, G. M. Hendricks, and M. Guo. 2012. Consistency, microstructure and probiotic survivability of goats' milk yoghurt using polymerized whey protein as a co-thickening agent. Int. Dairy J. 24:113-119.

Xia, X., B. Kong, J. Liu, X. Diao, and Q. Liu. 2012. Influence of different thawing methods on physicochemical changes and protein oxidation of porcine longissimus muscle. LWT Food Sci Technol. (Campinas.) 46:280-286. http://dx.doi.org/10.1016/j. lwt.2011.09.018. 